\title{
Hypertrophy and Karyomegaly
}

National Cancer Institute

\section{Source}

National Cancer Institute. Hypertrophy and Karyomegaly. NCI Thesaurus. Code C120892.

A finding of both hypertrophy and karyomegaly in the same lesion. 